\title{
Effect of the Serum Inhibited Gene (Si1) on Autophagy and Apoptosis in MCF-7 Breast Cancer Cells
}

\author{
Yu Lia Yong Cuib Wenxue Wang ${ }^{a}$ Mingxing Ma Meizhang Lia Deyong Tan ${ }^{a}$ \\ Suiyun Chen ${ }^{c}$
}

aLaboratory of Biochemistry and Molecular Biology, School of Life Sciences, Yunnan University, ${ }^{b}$ College of agriculture and Biotechnology, Yunnan Agricultural University, ' $P$ lant science institute of collage of life science, Yunnan University, Kunming, China

\section{Key Words}

Si1 Proliferation $•$ Cell cycle $\cdot$ Autophagy $\cdot$ Apoptosis $・$ MCF-7 cell

\begin{abstract}
Background/Aims: The serum inhibited gene (Si1) was named according to its inhibited expression in response to serum exposure. Si1 has an important relationship with tumors. Autophagy and apoptosis are two types of cell death. However, there are few studies regarding the association between Sil and autophagy, or apoptosis in tumors. In this, we investigated the effect of Sil on the proliferation and cell cycle progression of MCF-7 cells and its influence on autophagy and apoptosis in MCF-7 cells. Methods: To investigate these functions of Si1 in tumor cells, we firstly constructed a pEGFP-Sil overexpression vector and a pSilencer-Si1 interference vector, and we subsequently tested the proliferation and cell cycle progression of MCF-7 cells using the MTT assay and flow cytometry, and we then detected autophagy by western blotting and MDC (Monodansylcadaverine) staining as well as apoptosis by western blotting and Hoechst 33258 staining. Results: We found that the Sil gene can significantly inhibit the viability of MCF-7 cells and arrest the cell cycle at the G2/M phase. Sil can induce autophagy through upregulation of LC3- II and Beclin1, it can induce apoptosis through cleavage of PARP in MCF-7 cells. Conclusion: Altogether, our study indicated that Sil can inhibit cell proliferation of MCF-7, and also induces autophagy and apoptosis. This study firstly investigated the effect of Sil on autophagy and apoptosis in MCF-7 cells. Moreover, it also improves the current understanding of the mechanisms related to the effect of Sil on tumor cells and also provides a foundation for gene-targeted therapy.
\end{abstract}

\section{Introduction}

(C) 2017 The Author(s)

Published by S. Karger AG, Basel

The serum inhibited gene (Si1) (GenBank accession number: AY050169), also known as KANSL3 (Homo sapiens KAT8 regulatory NSL complex subunit 3). Tan and colleagues had primarily obtained from human glioma cell line U251 by comparing the differences in gene Y. Li and Y. Cui contributed equally to this work.

Meizhang Li, Deyong Tan and Suiyun Chen
Laboratory of Biochemistry and Molecular Biology, School of Life Sciences, Yunnan University, Kunming 650091 (China)

Tel. +86-0871-65032061, E-Mail mzhli@ynu.edu.cn / chensuiyun@ynu.edu.cn

\section{KARGER}




\section{Cellular Physiology Cell Physiol Biochem 2017;41:2268-2278

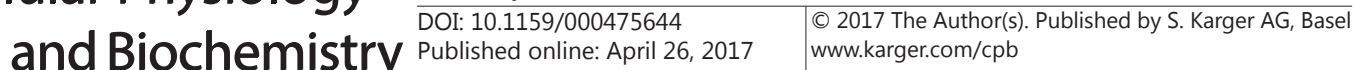

Li et al.: Si1 Induce Autophagy and Apoptosis in MCF-7

expression between normal cultured cells and serum-starved cells with the DD-PCR method [1]. The Si1 gene contains 5429 bp and 791 amino acid residues, we named it the serum inhibited gene (Si1) because its relationship with cell cycle regulation [2,3]. The Si1 gene potentially has some relationship with tumor development, because Si1 shares some similar expression characteristics with tumor susceptibility genes p16, p21 and p53 in serumstarved cells [4], and it is essential for spindle assembly and chromosome segregation [5]. Currently, there are very few papers describing the functions of the Si1 gene, and the definite function of the Si1 gene on development, apoptosis and autophagy in tumor is still not clearly understood.

It is well known that programmed cell death (PCD) is a terminal pathway for removal of damaged or abnormal cells to maintain homeostasis. Thus, at least three major types of programmed cell death have been identified, including autophagy, apoptosis and necrosis [68]. Autophagy is a self-degradation or digestion process of damaged or aged cells, proteins and organelles. Apoptosis is programmed cell death. Ashord and Porten firstly observed the phenomenon of autophagy by electron microscopy in 1962 [9]. Autophagy is a major mechanism by which a starving cell reallocates nutrients from unnecessary processes to more essential processes. Autophagy was firstly described in the 1960s, but many questions regarding the actual processes and mechanisms involved remain unanswered. The role of autophagy in disease is not well characterized; it may help to prevent or halt the progression of many diseases, such as atherosclerosis, cancer, neurodegenerative diseases and chronic infections [10]. However, in some situations, autophagy may actually contribute to the development of a disease $[11,12]$. Thus, understanding the mechanisms of the cancer together with the role of autophagy in tumors is critical to enhance the functions of anticancer therapies for patients with cancer.

Autophagy consists of the degradation and recycling of organelles and other cellular components in the cytosol so as to maintain cellular homeostasis [13]. Intracellular molecules and organelles, such as endoplasmic reticulum, mitochondria, and peroxisomes, are sequestered into double-membrane structures called autophagosomes [14]. Microtubule-associated protein light chain 3 (LC3), a mammalian homolog of yeast Atg8, has been used as a specific marker to monitor autophagy [15]. Upon induction of autophagy, LC3 is conjugated to phosphatidylethanolamine and targeted to autophagic membranes. Therefore, changes in LC3 localization have been used to measure autophagy [16].

Apoptosis occurs in multicellular organisms, and it was first proposed in 1972 by Kerr and colleagues [17]. Distinct biochemical events lead to the characteristic cell changes and death mediated by apoptosis signaling. These changes include blebbing, cell shrinkage, nuclear fragmentation, and chromosomal DNA fragmentation. Excessive apoptosis causes atrophy, whereas an insufficient amount of apoptosis results in uncontrolled cell proliferation, such as cancer [18]. Necrosis is in stark contrast to apoptosis, which is a naturally occurring cause of cell death. While apoptosis often provides beneficial effects to the organism, necrosis is almost always detrimental and can be fatal.

The aim of this study was to examine the effect of Si1 on autophagy and apoptosis in MCF-7 breast cancer cells. We found that the Si1 gene can suppress tumor proliferation and cell cycle arrest, moreover also promote the autophagy and apoptosis in MCF-7 tumor cells. This is the first report showing autophagy and apoptosis induced by Si1 in tumor cells and will provide an understanding of the effect of Si1 in tumor cells.

\section{Material and Methods}

Reagents and constructs

Medium were purchased from HyClone (UT, USA). A 3-(4,5-dimethyl-2-thiazolyl)-2,5-dimethyl-2Htetrazolium bromide (MTT) kit, trypan blue staining kit, Cell cycle kit, protein lysis buffer and Hoechst 33258 solution were purchased from Beyotime (Shanghai, China). Polyvinylidene difluoride (PVDF) membranes 


\section{Cellular Physiology Cell Physiol Biochem 2017;41:2268-2278 \begin{tabular}{l|l} 
and Biochemistry & $\begin{array}{l}\text { DOI: 10.1159/000475644 } \\
\text { Published } 2017 \text { The Author(s). Published by S. Karger AG, Basel } \\
\text { www.karger.com/cpb }\end{array}$
\end{tabular} \\ Published online: April 26, 2017, and Apoptosis in MCF-7}

were purchased from Millipore (Bedford, MA, USA). Anti-LC3, anti-Beclin1 and anti-poly(ADPribose) polymerase (PARP) antibodies were purchased from Cell Signaling Technology (MA, USA). The secondary antibodies, including horseradish peroxidase (HRP)-conjugated goat anti-mouse and anti-rabbit IgG, were purchased from the SANTA company. Restriction enzymes, DNA amplify enzymes, Primescript RT reagent Kit and SYBR Premix Ex Taq reagent Kit were purchased from the TAKARA company. Lipofectamine 2000 transfection reagent was purchased from Invitrogen.

\section{RNAi and Si1 over-expression}

The pEGFP neo plasmid was obtained from the biochemistry laboratory in Yunnan university. The human Si1 gene was cloned by PCR amplification with primers 5' AATCAAGCTTATGCCACTCTATGACAATCAGAAGG 3', which contains a Hind III site, and 5' GATAGGATCCGGGTGCTGGAGGCAGGCGCTGTGAG 3', which contains a BamH I site. The pSilencer 4.1-CMV neo vector was purchased from the Ambion company. We designed the siRNA oligo on Ambion's website and send the design to Invitrogen for synthesis. The Si1 gene SiRNA oligo, CAAGATCCTCAAAGCCCTG, is located at 166-187 bp in the Si1 gene sequence. We annealed the oligos using annealing buffer $(5 \times)$ at $95^{\circ} \mathrm{C}$ for two minutes in a PCR machine and then slowly placed the samples in the cold for approximately two h. After the ligation, we performed the transformation of the plasmids. All plasmids were verified by DNA sequencing (Shanghai Shenggong).

\section{Cells and cell cultures}

Human MCF-7, HepG2 and U251 cell lines were purchased from the ShangHai cells center. Cells were cultured in DMEM high glucose or RPMI 1640 and supplemented with 10\% fetal bovine serum (HyClone), 100 units $/ \mathrm{ml}$ penicillin (HyClone) and $100 \mu \mathrm{g} / \mathrm{ml}$ streptomycin (HyClone) at $37^{\circ} \mathrm{C}$ in a $5 \% \mathrm{CO}_{2}$ incubator.

\section{Cell Transfection}

Cells were transfected with the abovementioned plasmids using lipofectamine 2000 following the manufacturer's instructions. The cells were collected after transient transfection for further experiments.

\section{Cell viability assay}

Cell viability was assayed by trypan blue staining and the MTT assay. Cells were placed in a 96-well plate at a density of $8 \times 10^{3}$ cells/well for $24 \mathrm{~h}$, followed by transfection with the Si1-pEGFP vector for another $48 \mathrm{~h}$. After the treatment, for trypan blue staining, cells were collected with $0.25 \%$ trypsin in a $1.5 \mathrm{ml}$ tube, and $100 \mu$ Trypan blue $(2 \times)$ solution were added to the cells for $3 \mathrm{~min}$. We counted the total number of cells and the number of blue cells with a blood cell count plate. The cell survival ratio was calculated as follows: $(\%)=$ (total cells-blue cells) $/$ total cells $\times 100 \%$. For the MTT assay, $0.5 \mathrm{mg} / \mathrm{ml}$ MTT were added into each well for $4 \mathrm{~h}$. The supernatants were carefully aspirated, and the formazan crystals were dissolved using dimethyl sulfoxide (DMSO). Absorbance was measured at $570 \mathrm{~nm}$ with a spectral photometer (Molecular Devices).

\section{Cell cycle detection}

MCF-7 cells were transfected with vectors for $48 \mathrm{~h}$. Following the treatment, cells were harvested and fixed. After two washes with PBS, the cells were stained with a solution containing $50 \mu \mathrm{g} / \mathrm{ml}$ PI for 30 min in the dark at room temperature. Cells were analyzed by flow cytometry (Partec CyFlow).

\section{MDC staining}

MCF-7 cells were transfected with the vectors for $48 \mathrm{~h}$. MDC powder was purchased from Sigma and dissolved in DMSO at $0.1 \mathrm{~mol} / \mathrm{L}$ of the stock concentration. The working concentration was $50 \mu \mathrm{m} / \mathrm{L}$. The cells were incubated with the MDC dye for $45 \mathrm{~min}$ in the dark at $4^{\circ} \mathrm{C}$. The cells were then washed with PBS three times. The cells were visualized using a fluorescence microscope (Olympus). The autophagosomes appeared blue and presented in a punctate pattern with the cells.

\section{Detection of apoptosis}

Cells were transfected with the vectors for $48 \mathrm{~h}$. Apoptosis was analyzed using western blot for detection of PARP protein and Hoechst 33258 staining for the detection of nuclear. In brief, after transfection with the Si1-pEGFP vector for $48 \mathrm{~h}$, whole cells were fixed by $4 \%$ paraformaldehyde, and the washed by PBS. Subsequently, the cells were stained with Hoechst $33258(10 \mu \mathrm{g} / \mathrm{ml})$ for $5 \mathrm{~min}$, followed by analysis with a fluorescence microscope 


\section{Cellular Physiology Cell Physiol Biochem 2017;41:2268-2278

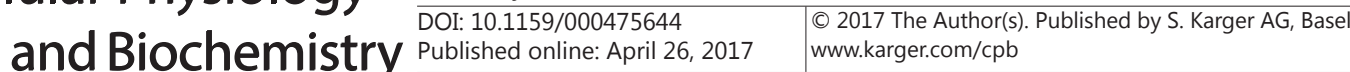 \\ Li et al.: Si1 Induce Autophagy and Apoptosis in MCF-7}

\section{Western blot}

Total protein extracts for western blot analysis were prepared using lysis buffer. Protein extracts (30 $\mu \mathrm{g}$ ) were subjected to $10 \%$ sodium dodecyl sulfate-polyacrylamide gel electrophoresis and transferred to polyvinylidene fluoride membranes (PVDF). The membranes were blocked with 5\% dry milk in PBS containing $0.2 \%$ Tween-20, followed by an incubation with primary antibodies and then an incubation with horseradish peroxidase-conjugated secondary antibodies. The bands were quantified and analyzed using ImageJ software and were normalized to the loading control ( $\beta$-actin). The following antibodies were used: anti- $\beta$-actin, anti-LC3, anti-Beclin1 and anti-PARP (Sigma-Aldrich, San Francisco, USA).

\section{Statistical analysis}

Data are presented as the mean \pm standard deviation from three independent experiments. Statistical significance was examined by one-way ANOVA using GraphPad Prism Version 5.0a (GraphPad Software) for comparing paired samples. P value less than 0.05 was considered statistically significant.

\section{Results}

\section{Plasmids}

We successfully constructed the pEGFP-Si1 and pSilencer-Si1 plasmids. The pEGFP-Si1 plasmid was identified by enzyme digestion and the DNA electrophoresis assay (Fig. 1C), and pSilencer-Si1 plasmid was assessed by the DNA electrophoresis assay (Fig. 1D). The maps of the neo pEGFP-N3 and pSilencer plasmids are shown in Fig. 1A and B, respectively. We also detected the expression of Si1 in MCF-7 cells treated with the pEGFP-Si1 and pSilencerSi1 plasmids for $48 \mathrm{~h}$ by using western blot and real-time PCR assay. As shown in Fig. 2,

A

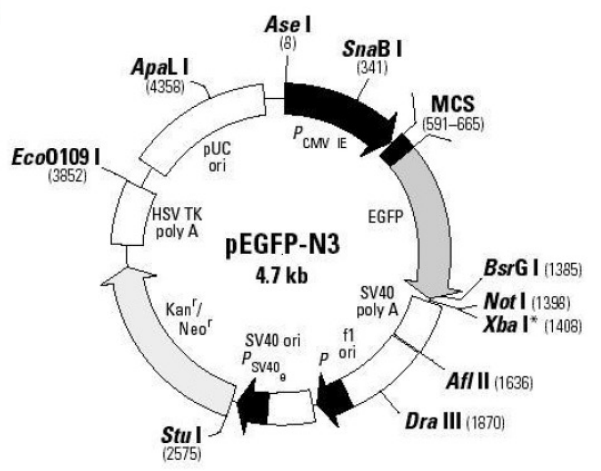

C

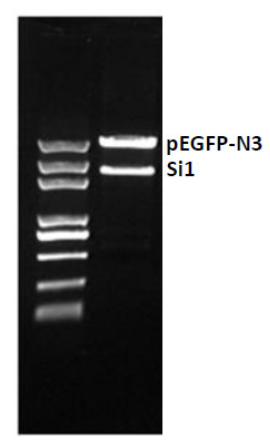

B

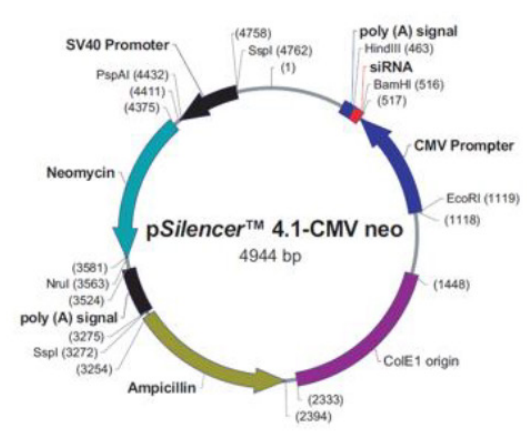

D

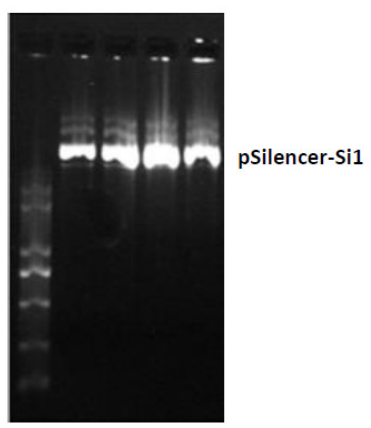

Fig. 1. The construction and verification of the pEGFP-Si1 and pSilencer-Si1 vectors. (A, B) The schematic profiles of the pEGFP-Si1 and pSilencer-Si1 vectors. (C, D) The identification of the pEGFP-Si1 and pSilencer-Si1 vectors by using agarose gel electrophoresis. DNA marker $(5000,3000,2000,1000,750,500,250$, $100 \mathrm{bp}$ ladder). 


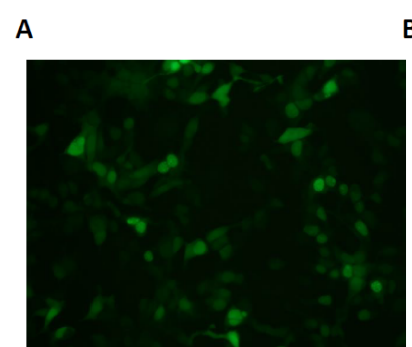

Si1

C

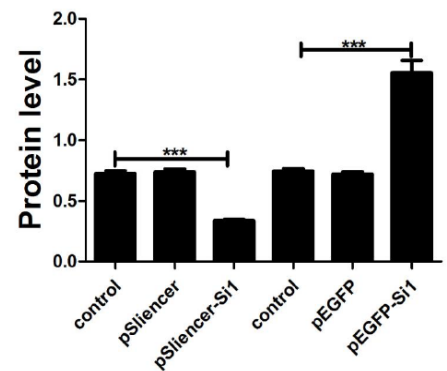

B

MCF-7 control pSliencer pSilencer-Si1 control pEGFP pEGFP-Si1

Sil

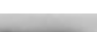

$\beta$-actin
D

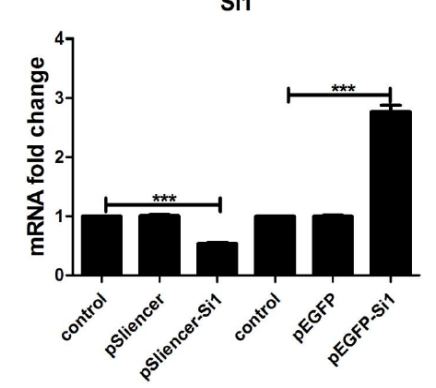

Fig. 2. The identifications of pEGFP-Si1 and pSilencer-Si1 vectors and its transfection efficiency in MCF-7. (A) Green fluorescence indicate expression of pEGFP-Si1 in MCF-7 cells under fluorescence microscopy. (B, C, D) The mRNA and protein expression levels of Si1 in different treated MCF-7 cells were determined by real-time quantitative PCR and western blot. Data from the quantitative PCR were analyzed using the $2^{-\Delta \Delta c t}$ formula, $\mathrm{n}=3$. $* \mathrm{P}<0.05$; ${ }^{* *} \mathrm{P}<0.01 ; * * * \mathrm{P}<0.001$.

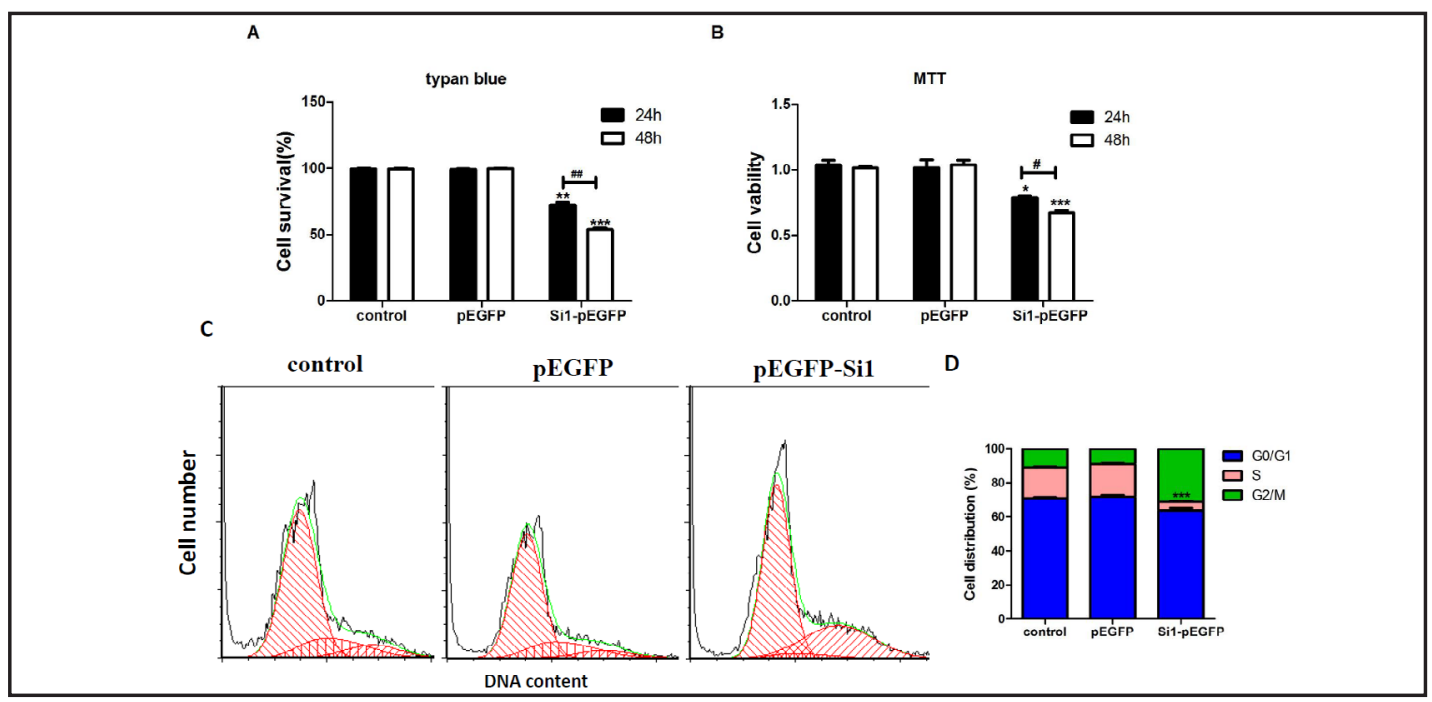

Fig. 3. The effect of Si1 on the proliferation in MCF-7 cells. (A) The results of cell viability in MCF-7 cells were obtained by trypan blue staining with the following formula for the survival ratio: $(\%)=($ total cells-blue cells)/total cells $\times 100 \%$. (B) The cell viability was determined by the MTT assay. MCF-7 cells were treated with Si1 overexpression for $24 \mathrm{~h}$ and $48 \mathrm{~h}$. (C, D) MCF-7 cells were treated with Si1 overexpression for 48 h. Cells were collected and analyzed by flow cytometry for identification of the cell cycle phase distribution. $\mathrm{n}=3$. ${ }^{*} \mathrm{P}<0.05 ;{ }^{* *} \mathrm{P}<0.01 ;{ }^{* * *} \mathrm{P}<0.001$.

Si1 was significantly over-expressed in the pEGFP-Si1 group and significantly inhibited in the pSilencer-Si1 group, and there were no differences between the pEGFP or pSilencer plasmids and the control plasmids.

\section{KARGER}


Fig. 4. The effect of Si1 on the autophagy in MCF-7 cells. (A) Expressions of LC3-II and Beclin1 protein in MCF-7 cells after treatment with Si1 for $48 \mathrm{~h}$ were detected by western blot. (B) The ratio of LC3-II to LC3-I was calculated to present the autophagic level. (C) Quantification analysis of Beclin1 protein level in MCF-7 cells. $\mathrm{n}=3$. ${ }^{*} \mathrm{P}<0.05 ;{ }^{* *} \mathrm{P}<0.01 ;{ }^{* * *} \mathrm{P}<0.001$.

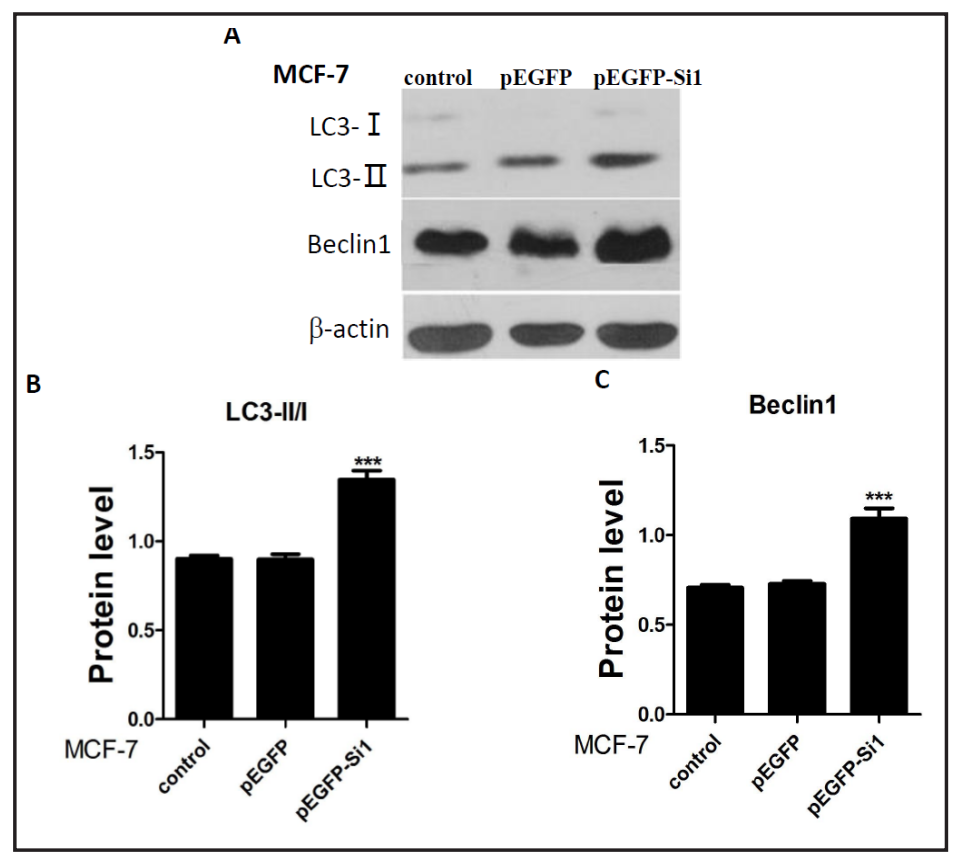

Si1 inhibited cell proliferation and cell cycle progression in MCF-7 cells

After the Si1-pEGFP and pEGFP vectors transfected the MCF-7 at 24 and $48 \mathrm{~h}$, cell viability was analyzed by trypan blue staining and the MTT assay. Trypan blue stains dead cells and not live cells; thus, we used it to distinguish between the dead and live cells. The result of the trypan blue staining indicated that the Si1-pEGFP group had a lower cell survival rate than that of the pEGFP vector group and the control (Fig. 3A). The MTT results showed that cell viability was significantly suppressed in the Si1-pEGFP group compared to the pEGFP vector group and the control (Fig. 3B). Moreover, there was no significant difference between the pEGFP vector group and the control. In addition, the proliferation inhibition ratio induced by Si1 in MCF-7 cells at $48 \mathrm{~h}$ was higher than that at $24 \mathrm{~h}$ (Fig. 3). Furthermore, we also detected the cell cycle progression of MCF-7 cells by flow cytometry. The flow cytometry results showed that Si1 induced G2/M phase arrest in MCF-7 cells (Fig. 3C and D). These findings indicated that Si1 can inhibit cell proliferation and induces mitotic arrest at the G2/M phase in MCF-7 cells.

\section{Si1 induced autophagy in MCF-7 cells}

Beclin1 and LC3 (microtubule-associated protein 1A/1B-light chain 3) genes play a pivotal role in mammalian autophagy. Beclin1 is involved in both the signaling pathway activating autophagy and in the initial step of autophagosome formation. To further investigate whether Si1 can influence autophagy in MCF-7 cells, we determined the levels of LC3 and Beclin 1 in MCF-7 cells with overexpression of the Si1 gene by western blot. The Si1pEGFP vector and/or pEGFP-N3 vectors were transiently transfected in MCF-7. After $48 \mathrm{~h}$, we observed changes in autophagy using a western blot. Western blotting analysis revealed that the expression level of LC3-II and Beclin1 increased significantly after treatment with Si1-pEGFP in MCF-7 cells (Fig. 4). These findings indicated that Si1 can induce autophagy in MCF-7 cells.

Si1 siRNA can suppress the autophagy induced by serum starvation in MCF-7 cells

To further investigate whether the autophagy of MCF-7 cells was induced by serum starvation, and whether Si1 siRNA can suppress autophagy induced by serum starvation in MCF-7 cells, we assessed LC3-II and Beclin1 in MCF-7 cells by western blot and MDC staining. Serum was deprived for $48 \mathrm{~h}$ in the serum starvation group. pSilencer-Si1 vector 
A

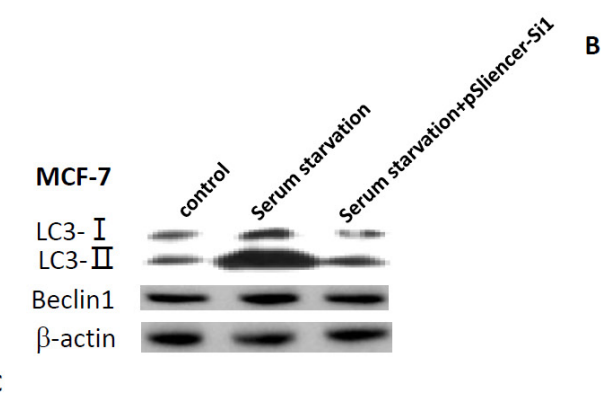

control

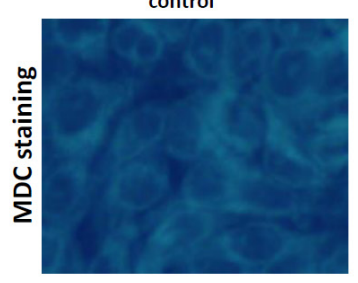

\begin{abstract}
pEGFP-Si1
\end{abstract}

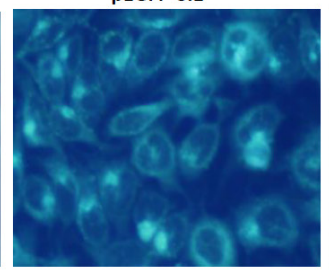

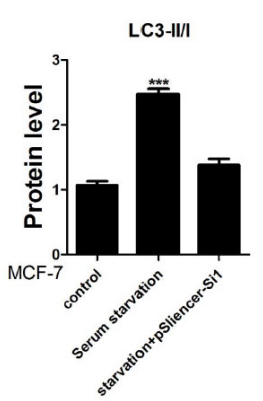

Serum starvation

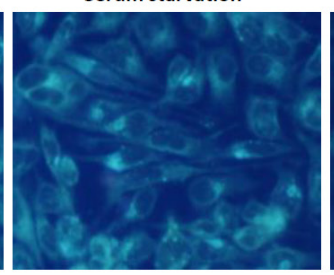

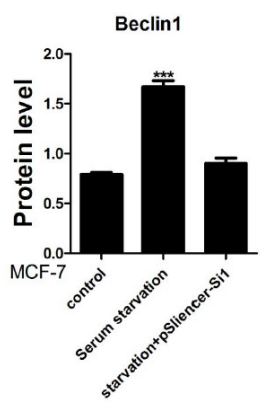

Serum starvation+pSliencer-Si1

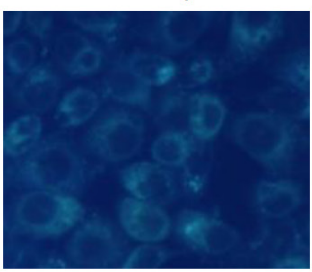

$\operatorname{MCF}-7(20 x)$

Fig. 5. The effect of Si1-siRNA on autophagy induced by serum starvation in MCF-7 cells. (A) Expressions of LC3 and Beclin1 proteins in MCF-7 cells after treatment with serum starvation and/or Si1-siRNA for 48 $\mathrm{h}$ were detected by western blot. (B) The ratio of LC3-II to LC3-I was calculated to present the autophagic level, and quantification analysis of Beclin1 protein level in MCF-7 cells. (C) Microscopic detection of autophagosomes in MCF-7 cells with different treatments for $48 \mathrm{~h}$. Autophagosomes were dyed by MDC staining which produced the blue fluorescence. $\mathrm{n}=3$. ${ }^{*} \mathrm{P}<0.05$; ${ }^{* *} \mathrm{P}<0.01$; ${ }^{* * *} \mathrm{P}<0.001$.

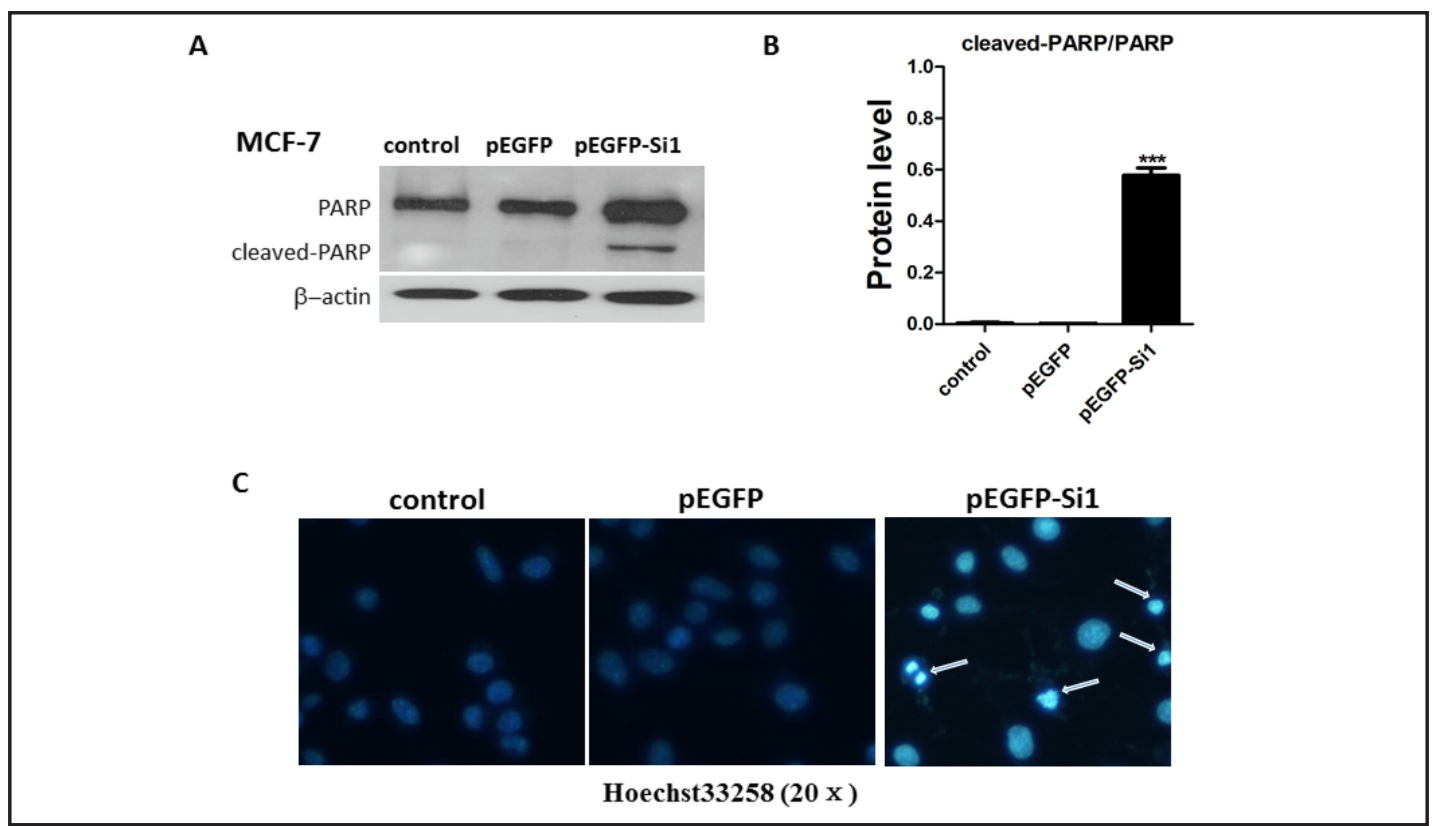

Fig. 6. The effect of Si1 on apoptosis in MCF-7 cells. (A) Western blotting analysis of PARP expression in MCF-7 cells with different treatments. (B) Quantitative analysis of the cleaved PARP protein level. (C) MCF-7 cells were treated with pEGFP and pEGFP-Si1 for $48 \mathrm{~h}$, respectively. And then above cells were stained with Hoechst 33258. $\mathrm{n}=3$. ${ }^{*} \mathrm{P}<0.05 ;{ }^{* *} \mathrm{P}<0.01 ;{ }^{* * *} \mathrm{P}<0.001$.

was transiently transfected in serum starvation+pSilencer-Si1 group. After $48 \mathrm{~h}$, we observed significantly increased expression levels of LC3-II and Beclin1 after serum starvation KARGER 
treatment in MCF-7 cells and found that Si1 siRNA can inhibit the increased levels of LC3-II and Beclin1 induced by serum starvation (Fig. 5A, B).

Furthermore, we detected the autophagosomes with blue florescent staining using a florescence microscope. We found that the more autophagosomes were located in the cytoplasm and exhibited much brighter blue florescence in both the serum starvation treated cells and Si1-pEGFP treated cells than in control cells, and the serum starvation+pSilencerSi1 group inhibited the serum starvation induced autophagy and was not significantly different from the control group (Fig. 5C). These results revealed that both serum starvation and Si1 can promote autophagy, and Si1 siRNA can markedly suppress autophagy induced by serum starvation in MCF-7 cells.

\section{Si1 induced apoptosis in MCF-7 cells}

To further identify whether Si1 can also influence apoptosis in MCF-7 cells, we assessed apoptosis using western blot and Hoechst 33258 staining. After Hoechst 33258 staining, morphologic changes of nuclear were tested by fluorescence microscope. Cells that showed reduced nuclear size, nuclear fragmentation and intense fluorescence were suggested the occurrence apoptosis, while normal nucleus showed rounded shapes and homogeneous staining. Our Hoechst 33258 staining assay showed that Si1 could induce the apoptosis in MCF-7 cells (Fig. 6C).

To further confirm the Si1-induced cell apoptosis, the expression level of PARP protein in MCF-7 cells was analyzed by Western blotting. The results indicated that the protein levels of cleaved-PARP increased in the Si1-treated cells (Fig. 6A, B). These findings clearly show that Si1 induces apoptosis in MCF-7 breast cancer cells.

\section{Discussion}

With advanced age, more people are suffering from cancer. Currently, chemotherapy is the primary treatment for cancer. However, many chemotherapeutic agents and drugs have adverse side effects, and chemotherapy not only kills the cancer cells but also impairs some normal cells during treatment $[19,20]$. Breast cancer is the most common type of malignancy in women worldwide and accounts for approximately $25 \%$ of total cancer cases and $15 \%$ of total cancer-related deaths [21]. Some researchers found that microRNA can regulate proliferation of breast cancer [22]. Therefore, it is of great importance to investigate potential gene therapy targets for the treatment of breast cancer.

The serum inhibited gene (Si1) is also named KANSL3, it can regulate some genes related to cell cycle progression. Cell cycle arrest and apoptosis are the two main inhibitors of proliferation [23]. Many anti-tumor-related genes and agents have shown different inhibitory activities by arresting the cell cycle at the G0/G1, S, or G2/M phases [24-26]. It was reported that Si1 was able to regulate microtubule stability both in cells and in vitro [27]. However, research focusing on in the role of Si1 in tumors is limited. Thus, it is much meaningful and interesting for researchers to investigate the effects of Si1 on tumors. In this study, we investigated the effect of the Si1 gene on the proliferation and cell cycle progression of MCF-7 breast cancer cells in vitro. We found that Si1 can significantly inhibit cell viability and arrest the cell cycle at the G2/M phase in MCF-7 breast cancer cells.

Recent findings support the view that autophagy regarded as a tumor suppressor as it can induce gene damage and chromosomal instability [28, 29]. Many studies have suggested that autophagy dysfunction also has close relationship with tumorigenesis and can affect the growth of tumor cells in some aspects, such as proliferation, the cell cycle and apoptosis [30, 31]. Levine and colleagues shown that autophagy can suppress tumors, mice with loss of Beclin1 are tumor-prone [32]. So, we hypothesize that Si1 also could affect the autophagy and apoptosis in MCF-7. With the understanding of the mechanisms of autophagy, researchers have increasingly focused on the relationship between tumor cells and autophagy [33]. However, autophagy is a double-edged sword and has different functions in different types 
of tumors. To understand the effect of Si1 on autophagy in MCF-7 cells, we detected the autophagy of MCF-7 cells with different treatments using western blot analysis. We found that Si1 could induce expression of LC3 and Beclin1 in MCF-7 cells. Above findings according with the view that Beclin1 was highly expression in some tumors, moreover Beclin1 expression inhibits the tumorigenicity of human breast cancer cells in mouse xenograft models [34,35]. According to reports, we know that the effect of autophagy in carcinogenesis is apparently complex because it was found to be protumorigenic in some studies but antitumorigenic in others [36]. Thus, the effect of Si1 on autophagy need further research in other tumor cells.

To further investigate the effect of Si1 on autophagy in MCF-7 cells, we detected the autophagy of MCF-7 cells with serum starvation and/or pSilencer-Si1 treatments using western blot analysis and MDC staining. Serum provided a broad spectrum of nutrients for cell growth [37]. The data showed that both Si1 and serum starvation could significantly induce the number of autophagosome and the expression of LC3- II and Becin1. However, the group of serum starvation+pSilencer-Si1 can significantly suppressed the serum starvation induced autophagy.

Many studies have revealed that tumorigenesis is closely associated with apoptosis, and some genes related to tumor cell apoptosis are becoming targets for tumor therapy [38]. Cleavage of PARP is one of the hallmarks of apoptosis [39]. To further investigate the effect of Si1 on MCF-7 cells, we also detected the apoptosis of MCF-7 cells with different treatments using Hoechst 33258 staining and western blot. Our western blot data clearly demonstrate the cleavage of PARP into the $85 \mathrm{kDa}$ fragment. Moreover, the Hoechst 33258 staining data show that Si1 significantly induced apoptosis in MCF-7 cells. These results clearly indicate that Si1 can inhibit cell proliferation and arrest the cell cycle, and promote the induction and activation of apoptosis in MCF-7 cells. This is the first study focused on the effects of the Si1 gene on the proliferation, autophagy and apoptosis of tumor cells. It implied that Si1 should be the focus of future research involving gene therapy for the treatment of tumors.

In conclusion, our results indicated that Si1 inhibited cell proliferation and induced cell cycle arrest in MCF-7 breast cancer cells. Si1 also induced autophagy via the upregulation of LC3- II and Beclin 1 and induced apoptosis via cleavage of PARP. Therefore, Si1 may become a potential therapeutic target for the development of future anti-cancer treatments.

\section{Disclosure Statement}

The authors have declared that no conflicts of interests exist.

\section{References}

1 Tan DY LJ, Qian W, Yu M, Chen Y, He J: Cloning of a Gene Inhibited by Serum Medium. Prog Biochem Biophys 2002;29: 816-819.

2 Yang K YJ, Qing Y, Guo Q, Wang KL, Yang Y, Tan DY: Initial study on a SNP site of Si-1 gene. Journal of Yunnan University 2004;26:450-453.

3 Zhao WX WH, Tan DY: Study of subcelluar-localization of Serum Inhibited Gene Si1 Protein. Prog Biochem Biophys 2009;36:840-846.

4 Luo L HY, Shu KX, Lai JH, Tan DY, Zhang H: The effects of serum to the gene expression of U251 cell line. Journal of Yunnan University 2000;22:144-147.

-5 Meunier S, Shvedunova M, Van Nguyen N, Avila L, Vernos I, Akhtar A: An epigenetic regulator emerges as microtubule minus-end binding and stabilizing factor in mitosis. Nat Commun 2015;6:7889.

-6 Eisenberg-Lerner A, Bialik S, Simon HU, Kimchi A: Life and death partners: apoptosis, autophagy and the cross-talk between them. Cell Death Differ 2009;16:966-975.

7 Denton D, Nicolson S, Kumar S: Cell death by autophagy: facts and apparent artefacts. Cell Death Differ 2012;19:87-95. 


\section{Cellular Physiology Cell Physiol Biochem 2017;41:2268-2278 \begin{tabular}{l|l} 
and Biochemistry Published onlıne: April 26, 2017 & $\begin{array}{l}\text { (c) } 2017 \text { The Author(s). Published by S. Karger AG, Basel } \\
\text { www.karger.com/cpb }\end{array}$
\end{tabular}}

8 Vandenabeele P, Galluzzi L, Vanden Berghe T, Kroemer G: Molecular mechanisms of necroptosis: an ordered cellular explosion. Nat Rev Mol Cell Biol 2010;11:700-714.

-9 Ashford TP, Porter KR: Cytoplasmic components in hepatic cell lysosomes. J Cell Biol 1962;12:198-202.

10 Gewirtz DA: The four faces of autophagy: implications for cancer therapy. Cancer Res 2014;74:647-651.

11 Hu YL, Jahangiri A, Delay M, Aghi MK: Tumor cell autophagy as an adaptive response mediating resistance to treatments such as antiangiogenic therapy. Cancer Res 2012;72:4294-4299.

12 Zou Z, Yuan Z, Zhang Q, Long Z, Chen J, Tang Z, Zhu Y, Chen S, Xu J, Yan M, Wang J, Liu Q: Aurora kinase A inhibition-induced autophagy triggers drug resistance in breast cancer cells. Autophagy 2012;8:17981810.

13 Eskelinen EL, Saftig P: Autophagy: a lysosomal degradation pathway with a central role in health and disease. Biochim Biophys Acta 2009;1793:664-673.

14 Maiuri MC, Zalckvar E, Kimchi A, Kroemer G: Self-eating and self-killing: crosstalk between autophagy and apoptosis. Nat Rev Mol Cell Biol 2007;8:741-752.

15 Kabeya Y, Mizushima N, Ueno T, Yamamoto A, Kirisako T, Noda T, Kominami E, Ohsumi Y, Yoshimori T: LC3, a mammalian homologue of yeast Apg8p, is localized in autophagosome membranes after processing. EMBO J 2000;19:5720-5728.

16 Kuma A, Matsui M, Mizushima N: LC3, an autophagosome marker, can be incorporated into protein aggregates independent of autophagy: caution in the interpretation of LC3 localization. Autophagy 2007;3:323-328.

17 Kerr JF, Wyllie AH, Currie AR: Apoptosis: a basic biological phenomenon with wide-ranging implications in tissue kinetics. Br J Cancer 1972;26:239-257.

18 Thompson CB: Apoptosis in the pathogenesis and treatment of disease. Science 1995;267:1456-1462.

19 Pabla N, Dong G, Jiang M, Huang S, Kumar MV, Messing RO, Dong Z: Inhibition of PKCdelta reduces cisplatininduced nephrotoxicity without blocking chemotherapeutic efficacy in mouse models of cancer. J Clin Invest 2011;121:2709-2722.

20 El-Sayyad HI, Ismail MF, Shalaby FM, Abou-El-Magd RF, Gaur RL, Fernando A, Raj MH, Ouhtit A: Histopathological effects of cisplatin, doxorubicin and 5-flurouracil (5-FU) on the liver of male albino rats. Int J Biol Sci 2009;5:466-473.

21 Jemal A, Bray F, Center MM, Ferlay J, Ward E, Forman D: Global cancer statistics. CA Cancer J Clin 2011;61:69-90.

22 Zhao S, Han J, Zheng L, Yang Z, Zhao L, Lv Y: MicroRNA-203 Regulates Growth and Metastasis of Breast Cancer. Cell Physiol Biochem 2015;37:35-42.

23 Chan KT, Meng FY, Li Q, Ho CY, Lam TS, To Y, Lee WH, Li M, Chu KH, Toh M: Cucurbitacin B induces apoptosis and S phase cell cycle arrest in BEL-7402 human hepatocellular carcinoma cells and is effective via oral administration. Cancer Lett 2010;294:118-124.

24 Lu YJ, Yang SH, Chien CM, Lin YH, Hu XW, Wu ZZ, Wu MJ, Lin SR: Induction of G2/M phase arrest and apoptosis by a novel enediyne derivative, THDB, in chronic myeloid leukemia (HL-60) cells. Toxicol In Vitro 2007;21:90-98.

25 Orren DK, Petersen LN, Bohr VA: Persistent DNA damage inhibits S-phase and G2 progression, and results in apoptosis. Mol Biol Cell 1997;8:1129-1142.

26 Gamet-Payrastre L, Li P, Lumeau S, Cassar G, Dupont MA, Chevolleau S, Gasc N, Tulliez J, Terce F: Sulforaphane, a naturally occurring isothiocyanate, induces cell cycle arrest and apoptosis in HT29 human colon cancer cells. Cancer Res 2000;60:1426-1433.

27 Yokoyama H, Gruss OJ: New mitotic regulators released from chromatin. Front Oncol 2013;3:308.

28 Mathew R, Kongara S, Beaudoin B, Karp CM, Bray K, Degenhardt K, Chen G, Jin S, White E: Autophagy suppresses tumor progression by limiting chromosomal instability. Genes Dev 2007;21:1367-1381.

29 Karantza-Wadsworth V, Patel S, Kravchuk O, Chen G, Mathew R, Jin S, White E: Autophagy mitigates metabolic stress and genome damage in mammary tumorigenesis. Genes Dev 2007;21:1621-1635.

-30 Mizushima N, Levine B, Cuervo AM, Klionsky DJ: Autophagy fights disease through cellular self-digestion. Nature 2008;451:1069-1075.

- 31 Levine B, Kroemer G: Autophagy in the pathogenesis of disease. Cell 2008;132:27-42.

- 32 Qu X, Yu J, Bhagat G, Furuya N, Hibshoosh H, Troxel A, Rosen J, Eskelinen EL, Mizushima N, Ohsumi Y, Cattoretti G, Levine B: Promotion of tumorigenesis by heterozygous disruption of the beclin 1 autophagy gene. J Clin Invest 2003;112:1809-1820. 


\section{Cellular Physiology Cell Physiol Biochem 2017;41:2268-2278 \begin{tabular}{l|l} 
DOI: 10.1159/000475644 & $\begin{array}{l}\text { O 2017 The Author(s). Published by S. Karger AG, Basel } \\
\text { www.karger.com/cpb }\end{array}$ \\
\hline
\end{tabular}}

Li et al.: Si1 Induce Autophagy and Apoptosis in MCF-7

33 Zalckvar E, Yosef N, Reef S, Ber Y, Rubinstein AD, Mor I, Sharan R, Ruppin E, Kimchi A: A systems level strategy for analyzing the cell death network: implication in exploring the apoptosis/autophagy connection. Cell Death Differ 2010;17:1244-1253.

-34 Liang XH, Jackson S, Seaman M, Brown K, Kempkes B, Hibshoosh H, Levine B: Induction of autophagy and inhibition of tumorigenesis by beclin 1. Nature 1999;402:672-676.

-35 Miracco C, Cosci E, Oliveri G, Luzi P, Pacenti L, Monciatti I, Mannucci S, De Nisi MC, Toscano M, Malagnino V, Falzarano SM, Pirtoli L, Tosi P: Protein and mRNA expression of autophagy gene Beclin 1 in human brain tumours. Int J Oncol 2007;30:429-436.

-36 Tian Y, Wang L, Ou JH: Autophagy, a double-edged sword in hepatocarcinogenesis. Mol Cell Oncol 2015;2:e1004968.

37 Xu J, Huang G, Zhang Z, Zhao J, Zhang M, Wang Y, Liu Z, Lu J: Up-Regulation of Glioma-Associated Oncogene Homolog 1 Expression by Serum Starvation Promotes Cell Survival in ER-Positive Breast Cancer Cells. Cell Physiol Biochem 2015;36:1862-1876.

38 Kasibhatla S, Tseng B: Why target apoptosis in cancer treatment? Mol Cancer Ther 2003;2:573-580.

-39 Gong X, Wang M, Wu Z, Tashiro S, Onodera S, Ikejima T: Pseudolaric acid B induces apoptosis via activation of c-Jun N-terminal kinase and caspase-3 in HeLa cells. Exp Mol Med 2004;36:551-556. 